\title{
CITIZENSHIP AS CRIMINALLY SIGNIFICANT INFORMATION IN THE INVESTIGATION OF CRIMES INVOLVING FOREIGN CITIZENS
}

\author{
Anna I. Zemskova \\ Volgograd Academy of the Ministry of Internal Affairs of the Russian Federation, Volgograd, Russian Federation
}

Introduction: the paper discusses some features of setting up the investigation of crimes involving foreign citizens as witnesses and victims, depending on their citizenship. The goal is to analyze the norms of international law and the legislation of the Russian Federation for the criminalistic significance and the influence of the citizenship of a foreign citizen involved in the criminal proceedings on setting up the crime investigation. Using the simulation method, the possible investigative situations were considered, during which the influence of citizenship of foreign citizens on the course of crime investigation was demonstrated. Conclusions: in practice, for the investigator and interrogator, the participation of a foreigner in the criminal process creates the need for additional organizational measures, which, first of all, are due to his / her citizenship to a specific foreign state. The efficiency of the investigation of crimes involving foreign citizens will largely depend on the legal competence of the investigator in the matters of the migration legislation of the Russian Federation.

Key words: foreign citizen, legal status of foreign citizens, citizenship, criminal proceedings, witness, victim, investigator.

Citation. Zemskova A.I. Citizenship as Criminally Significant Information in the Investigation of Crimes Involving Foreign Citizens. Legal Concept, 2020, vol. 19, no. 1, pp. 126-131. (in Russian). DOI: https://doi.org/ 10.15688/lc.jvolsu.2020.1.18

УДК 343.985 .7

Дата поступления статьи: 10.01.2020

ББК 67.73

Дата принятия статьи: 31.01 .2020

\section{ГРАЖДАНСКАЯ ПРИНАДЛЕЖНОСТЬ КАК КРИМИНАЛИСТИЧЕСКИ ЗНАЧИМАЯ ИНФОРМАЦИЯ ПРИ РАССЛЕДОВАНИИ ПРЕСТУПЛЕНИЙ С УЧАСТИЕМ ИНОСТРАННЫХ ГРАЖДАН}

\author{
Анна Игоревна Земскова \\ Волгоградская академия МВД России, г. Волгоград, Российская Федерация
}

\begin{abstract}
Введение: в статье рассматриваются некоторые особенности организации расследования преступлений с участием иностранных граждан в качестве свидетелей и потерпевших в зависимости от их гражданской принадлежности. Цель состоит в анализе норм международного права и законодательства Российской Федерации на предмет криминалистической значимости и влияния гражданской принадлежности иностранного гражданина, вовлекаемого в уголовный процесс, на организацию расследования преступле은 ний. С помощью метода моделирования были рассмотрены возможные следственные ситуации, в ходе которых продемонстрировано влияние гражданства иностранных граждан на ход расследования преступления. Выводы: на практике для следователя и дознавателя участие иностранца в уголовном процессе создает необходимость проведения дополнительных организационных мероприятий, которые в первую \% очередь обусловлены его гражданской принадлежностью к конкретному иностранному государству. Эффективность деятельности по расследованию преступлений с участием иностранных граждан будет в значительной степени зависеть от правовой грамотности следователя в вопросах миграционного законода(2) тельства Российской Федерации.
\end{abstract}


Ключевые слова: иностранный гражданин, правовое положение иностранных граждан, гражданство, уголовный процесс, свидетель, потерпевший, следователь.

Цитирование. Земскова А. И. Гражданская принадлежность как криминалистически значимая информация при расследовании преступлений с участием иностранных граждан // Legal Concept = Правовая парадигма. - 2020. - Т. 19, № 1. -C. 126-131. -DOI: https://doi.org/10.15688/lc.jvolsu.2020.1.18

\section{Введение}

Иностранным гражданам, которые стали участниками уголовного процесса, гарантирован перечень прав, при этом, например, право иностранного гражданина в российском уголовном процессе на государственную защиту и юридическую поддержку со стороны своего государства зачастую зависит от наличия и характера международных отношений между Российской Федерацией и государством гражданской принадлежности конкретного иностранца - участника уголовного процесса.

На наш взгляд, это говорит о наличии у каждого иностранного гражданина специального статуса (в рамках общеправового), особенности которого зависят от ряда причин и, прежде всего, от его гражданства или подданства.

Объективно предположить, что при исследовании общеправового статуса иностранца, как участника уголовного процесса, включение в его структуру гражданства в качестве одного из основных элементов просто необходимо. В качестве подтверждения этой позиции служит исследование Г.А. Якимова, который, опираясь на работы Н.В. Витрука, Л.Д. Воеводина, В.В. Невинского, Н.И. Матузова, В.А. Патюлина и других ученых, выделяет в качестве базовых элементов правового статуса личности юридические права и обязанности, принципы права, правосубъектность, юридические гарантии прав и обязанностей, юридическую ответственность, а также правоотношения общего (статусного) характера и правовые нормы, основой которых выступает институт гражданства [8].

\section{Бипатризм и апатризм участников уголовного процесса}

Научные споры и многообразие попыток выявления сущности гражданства объясняются тем, что в его содержании непрерывно про- исходят изменения, обусловленные конкретными историческими событиями в мире.

Рассматривая гражданство, как элемент правового статуса иностранного гражданина, необходимо указать, что в сфере межгосударственных отношений в ряде случаев неизбежно возникают коллизии, порождающие такие явления, как бипатризм (двойное гражданство) и апатризм (отсутствие принадлежности к гражданству какого-либо государства).

В практической деятельности следователя, помимо ограниченного срока пребывания, вовлечение лица без гражданства в уголовный процесс может быть осложнено невозможностью получения характеризующей информации личности апатрида, ввиду отсутствия достоверной информации о месте его постоянного проживания.

В отношении лиц с двойным гражданством возникают трудности в сфере межгосударственных отношений, так как, с одной стороны, может возникнуть спор о гражданстве лица между государствами, рассматривающими его как своего гражданина, а с другой - по каким-либо причинам третье государство может быть вынуждено решать, какому гражданству лица с двойным гражданством следует отдать предпочтение [4, с. 118 ].

$\mathrm{C}$ похожей ситуацией может столкнуться следователь в случае вовлечения в уголовный процесс иностранца, имеющего гражданство нескольких стран. В этом случае необходимо выяснить, какие международные договоры заключены между Россией и государствами гражданской принадлежности бипатрида, а также рассмотреть вопрос о наличии международных договоренностей между иностранными государствами, гражданство которых он имеет. Исходя из содержания ст. 1 УПК, как только в уголовном процессе появляется участник-иностранец, задача следователя - реализовать его права, предусмотренные не только УПК, но и международными договорами с государством его гражданства. 
В Соглашении между Российской Федерацией и Таджикистаном об урегулировании вопросов двойного гражданства отмечается, что оно заключается в целях дальнейшего развития дружественных отношений между странами и исходит из стремления к справедливому и гуманному урегулированию вопросов, связанных с двойным гражданством [1]. В Соглашении говорится, что каждая из сторон признает за своими гражданами право приобрести, не утрачивая ее гражданства, гражданство другой стороны. На сегодняшний день это единственное действующее соглашение России о признании двойного гражданства. Таким образом, на ее территории только граждане Республики Таджикистан, являющиеся российскими гражданами, имеют юридическое двойное гражданство, соответственно могут пользоваться правами и нести обязанности как граждане России и как граждане Таджикистана.

В иных случаях граждане Российской Федерации, имеющие гражданство или подданство иностранного государства, в соответствии с ч. 1 ст. 6 Федерального закона от 31 мая 2002 г. № 62-Ф3 «О гражданстве Российской Федерации» будут рассматриваться только как граждане России. Иностранным гражданина в Российской Федерации будут считать только при условии отсутствия у него российского гражданства и «доказательства» наличия у него гражданства (подданства) иностранного государства [7].

\section{Некоторые особенности влияния} гражданской принадлежности иностранных граждан, вовлекаемых в уголовный процесс, на ход расследования

«Доказательством» наличия гражданства или подданства иностранного государства является в первую очередь паспорт или иной документ, удостоверяющий личность и гражданство, признаваемый в этом качестве в рамках международно-правовых отношений России с другими странами.

Чаще всего документом, удостоверяющим личность и гражданство иностранного гражданина, является заграничный паспорт, который бывает дипломатическим, служебным и национальным (общегражданским).
Необходимо отметить, что в практической деятельности следователя (дознавателя) иностранцы, вовлекаемые в уголовный процесс в качестве свидетелей (потерпевших), являются владельцами «обычных» национальных паспортов. Это иностранные граждане, которые находятся в России временно или постоянно и подчинены юрисдикции государства, где они пребывают, в полном объеме (трудовые мигранты, иностранные студенты, туристы и т. д.).

Помимо определения правового статуса паспорт иностранца является источником достоверных персональных данных. Ведь в первую очередь следователю необходимо установить личность иностранного гражданина и законность его пребывания в России.

На основе автоматизированных учетов и базы биометрических персональных данных подразделений МВД России; банка данных об осуществлении иностранными гражданами трудовой деятельности и иных информационных систем, содержащих информацию об иностранных гражданах и лицах без гражданства, в России формируется Центральный банк данных по учету иностранных граждан. Согласно Постановлению Правительства Российской Федерации от 14 февраля 2007 г. № 94 им является государственная информационная система миграционного учета (далее ГИСМУ). ГИСМУ содержит «досье» на каждого иностранного гражданина, въезжающего в Российскую Федерацию, с указанием сведений о его правовом статусе, нарушениях российского законодательства, датах въезда и выезда из России и т. д. [3, с. 93].

Ранее государственным заказчиком и координатором работ по формированию и обеспечению функционирования ГИСМУ являлась Федеральная миграционная служба (далее - ФМС). Указом Президента Российской Федерации № 156 от 5 апреля 2016 г. [6] ФМС была упразднена, а ее функции и полномочия переданы Министерству внутренних дел Российской Федерации. На практике подразделения ФМС были переведены в подчинение МВД России и стали управлениями и отделами по вопросам миграции в системе ОВД. Сотрудники других подразделений МВД доступа к ГИСМУ в большинстве своем до настоящего времени не получили. 
Рассмотрим пример, как гражданство иностранного гражданина может повлиять на его вовлечение в уголовный процесс в качестве свидетеля (потерпевшего).

Иностранная гражданка, осуществляя розничную торговлю на территории рынка, стала свидетелем преступления. При проверке ее документов было установлено, что женщина имеет гражданство Республики Армения и статус временно пребывающего иностранного гражданина. Цель ее пребывания - «работа» - была указана в миграционной карте, при этом патента на осуществление трудовой деятельности, который в обязательном порядке оформляется иностранными работниками, прибывшими в Россию в безвизовом порядке, женщина не получала. Разрешенный срок ее пребывания истекал на момент проверки документов через 5 дней. Следователю, без учета армянского гражданства, пришлось бы работать со свидетелем изначально в условиях конфликтной ситуации, так как иностранная гражданка осуществляла трудовую деятельность с нарушением установленного порядка и ввиду нежелания негативных в связи с этим последствий могла отказаться от дачи показаний, либо применение к ней мер административной ответственности за выявленное нарушение не способствовало бы формированию доверительного отношения свидетеля к следователю и оказанию ему содействия в расследовании. Кроме того, учитывая правовой статус временно пребывающего иностранного гражданина, следователю пришлось бы проводить первичные мероприятия в условиях сжатых сроков.

Республика Армения Договором, подписанным 10 октября 2014 г. в г. Минске, присоединилась к Договору о Евразийском экономическом союзе от 29 мая 2014 года [2]. Согласно ст. 97 указанного международного договора работодатели и (или) заказчики работ (услуг) государства-члена вправе привлекать к осуществлению трудовой деятельности трудящихся государств-членов без учета ограничений по защите национального рынка труда. При этом трудящимся государств-членов не требуется получение разрешения на осуществление трудовой деятельности в государстве трудоустройства.
Таким образом, наличие гражданства Армении в рамках международных договоренностей дает право осуществлять гражданам Армении на территории России трудовую деятельность без дополнительных разрешений и патентов. Достаточно наличия трудового договора, который может быть неоднократно пролонгирован, и к тому же является основанием для продления срока пребывания в Российской Федерации. В рассматриваемом примере гражданка Армении не нарушала установленный порядок осуществления трудовой деятельности, так как с ней правомерно был заключен трудовой договор и пролонгирован, в связи с чем соответствующие документы о продлении разрешенного срока пребывания указанной гражданке были представлены в отдел по вопросам миграции МВД России. Таким образом, гражданство Республики Армения и сложившиеся обстоятельства пребывания иностранной гражданки будут способствовать ее вовлечению в уголовный процесс в качестве свидетеля.

Можно сделать вывод, что такая характеристика общеправового статуса иностранца, как гражданская принадлежность и факт наличия документа, удостоверяющего личность и гражданство, позволяют следователю, предварительно изучив международноправовые документы, регламентирующие отношения Российской Федерации с конкретным государством, определить наличие дополнительных ограничений или привилегий. Достоверные персональные данные иностранца могут быть использованы для проведения проверок по оперативным и специальным учетам МВД. При помощи ГИСМУ следователь может определить специфику правового статуса иностранного гражданина с точки зрения разрешенного срока пребывания, цели въезда и допущенных им административно-правовых нарушений. Данная информация об иностранном гражданине, безусловно, является криминалистически значимой, так как она характеризует личность участника уголовного процесса и поможет следователю в раскрытии и расследовании преступления с его участием.

Проверка иностранного гражданина по ГИСМУ выявляет еще одну важную характеристику общеправового статуса иностранца - законность пребывания (проживания) в 
Российской Федерации. Изучение документов иностранца, даже при условии осведомленности проверяющего лица об особенностях документального оформления различного правового статуса иностранного гражданина, может не дать достоверных сведений о законности его нахождения в Российской Федерации.

Например, уполномоченным органом (учреждением) в отношении иностранного гражданина может быть принято решение об аннулировании разрешения на временное проживание или вида на жительство, либо решение о сокращении срока пребывания в России. Перечень оснований для принятия таких решений предусмотрен миграционным законодательством Российской Федерации. О данных решениях иностранный гражданин уведомляется в установленном порядке, но может уклоняться от явки для проставления соответствующих отметок в документы (паспорт, миграционную карту).

При этом информация о сокращении срока пребывания и аннулировании разрешительных документов вносится в ГИСМУ. Поэтому сделать однозначный вывод о законности пребывания (проживания) иностранца можно только после проверки его персональных данных по ГИСМУ.

Незаконность пребывания иностранца в России как характеристика его правового статуса влечет необходимость проведения комплекса действий, предусмотренных законодательством Российской Федерации.

Рассмотрим пример, как незаконное пребывание иностранного гражданина в России может повлиять на его вовлечение в уголовный процесс в качестве потерпевшего или свидетеля.

Иностранный гражданин стал жертвой преступления и обратился с заявлением в правоохранительные органы. В ходе проверки по учетам ГИСМУ было установлено, что он уклоняется от выезда из России по истечении разрешенного срока пребывания. Ответственность за данное нарушение регламентирована ст. 18.8 Кодекса об административных правонарушениях Российской Федерации, в соответствии с которой предусмотрено наказание в виде штрафа с административным выдворением за пределы России [5]. Суд, при условии злостного уклонения от выезда и от- сутствия места проживания (пребывания), вероятнее всего, вынесет в отношении указанного иностранного гражданина решение о принудительном выдворении с содержанием в специальном учреждении для незаконных мигрантов. В этой связи следователю в рамках проведения расследования необходимо будет решать организационные вопросы доставления иностранца из Центра временного содержания мигрантов для участия в проверочных мероприятиях и следственных действиях. Кроме того, спрогнозировать срок, в течение которого иностранный гражданин все еще будет находиться на территории России, практически невозможно, так как он зависит от необходимости оформления документов для выезда (национальный паспорт, выездная виза), от урегулирования вопроса обеспечения проездными документами, а для этого установления стороны, ранее приглашающей иностранного гражданина в Российскую Федерацию.

\section{Выводы}

Таким образом, несмотря на то что иностранные граждане равны в правах и обязанностях с гражданами России, на практике для следователя и дознавателя участие иностранца в уголовном процессе создает необходимость проведения дополнительных организационных мероприятий, которые в первую очередь обусловлены его гражданской принадлежностью к конкретному иностранному государству. Эффективность деятельности по расследованию преступлений с участием иностранных граждан будет в значительной степени зависеть от правовой грамотности следователя в вопросах миграционного законодательства Российской Федерации.

\section{СПИСОК ЛИТЕРАТУРЫ}

1. Бюллетень международных договоров. 1995. - № 10.

2. Договор о Евразийском экономическом союзе (подписан в г. Астане 29.05.2014). - Доступ из справ.-правовой системы «КонсультантПлюс» (дата обращения: 12.12.2019).

3. Земскова, А. И. К вопросу об особенностях участия иностранных граждан в уголовном про- 
цессе Российской Федерации в качестве свидетелей и потерпевших / А. И. Земскова // Вестник Волгоградской академии МВД России. - 2017. - № 3.

4. Калинин, В. Н. Институт гражданства в российском праве (общетеоретический аспект) : дис. ... канд. юрид. наук / Калинин Владимир Николаевич. М., 2002. $-226 \mathrm{c}$.

5. Кодекс Российской Федерации об административных правонарушениях от 30.12.2001 № 195-Ф3 (ред. от 27.12.2019). - Доступ из справ.-правовой системы «КонсультантПлюс» (дата обращения: 12.12.2019).

6. Указ Президента РФ от 05.04.2016 № 156 (ред. от 21.12.2016) «О совершенствовании государственного управления в сфере контроля за оборотом наркотических средств, психотропных веществ и их прекурсоров и в сфере миграции». - Доступ из справ.-правовой системы «КонсультантПлюс» (дата обращения: 12.12.2019).

7. Федеральный закон РФ от 31.05.2002 № 62-Ф3 «О гражданстве Российской Федерации» (ред. от 26.07.2019). - Доступ из справ.-правовой системы «КонсультантПлюс» (дата обращения: 12.12.2019).

8. Якимов, Г. А. Правовой статус личности: проблемы природы и элементного состава / Г. А. Якимов // Рос. юрид. журн. - 2008. - № 2.

\section{REFERENCES}

1. Byulleten mezhdunarodnykh dogovorov [Bulletin of International Treaties], 1995, no. 10.

2. Dogovor o Evraziyskom ekonomicheskom soyuze (podpisan v g. Astane 29.05.2014) [The Agreement on the Eurasian Economic Union (Signed in Astana on 29.05.2014)]. Access from Reference Legal System "ConsultantPlus".

3. Zemskova A.I. K voprosu ob osobennostyakh uchastiya inostrannykh grazhdan $\mathrm{v}$ ugolovnom protsesse Rossiyskoy Federatsii v kachestve svideteley i poterpevshikh [To the Question About the Participation of Foreign Citizens in the Criminal Process of the Russian Federation as Witnesses and Victims]. Vestnik Volgogradskoy akademii MVD Rossii [Scientific and Methodical Journal "Bulletin of Volgograd Academy of the MIA of Russia”], 2017, no. 3.

4. Kalinin V.N. Institut grazhdanstva $v$ rossiyskom prave (obshcheteoreticheskiy aspekt): dis. ... kand. yurid. nauk [Institute of Citizenship in Russian Law (General Theoretical Aspect). Cand. jurid. sci. diss.]. Moscow, 2002. 226 p.

5. Kodeks Rossiyskoy Federatsii ob administrativnykh pravonarusheniyakh ot 30.12.2001 № 195-FZ: (red. ot 27.12.2019) [Code of the Russian Federation on Administrative Offences of December 30, 2001 no. 195-FZ (ed. of December 27, 2019). Access from Reference Legal System "ConsultantPlus" (accessed 12 December 2019).

6. Ukaz Prezidenta RF ot 05.04.2016 № 156 (red. ot 21.12.2016) «O sovershenstvovanii gosudarstvennogo upravleniya v sfere kontrolya za oborotom narkoticheskikh sredstv. psikhotropnykh veshchestv i ikh prekursorov i v sfere migratsii» [Decree of the President of the Russian Federation of April 05, 2016 no. 156(ed. of December 21, 2016) "On Improving Public Administration in the Sphere of Control Over the Circulation of Narcotic Drugs, Psychotropic Substances and Their Precursors and in the Field of Migration"']. Access from Reference Legal System "ConsultantPlus" (accessed 12 December 2019).

7. Federalnyy zakon RF ot 31.05.2002 № 62-FZ «O grazhdanstve RossiyskoyFederatsii» (red. ot 26.07.2019) [Federal Law of the Russian Federation of May 31, 2002 no. 62-FZ "On Citizenship of the Russian Federation" (ed. of Jule 26, 2019). Access from Reference Legal System "ConsultantPlus" (accessed 12 December 2019).

8. Yakimov G.A. Pravovoy status lichnosti: problemy prirody i elementnogo sostava [Legal Status of the Individual: Problems of Nature and Elemental Composition]. Ros. yurid. zhurn. [Russian Law Journal], 2008, no. 2.

\section{Information About the Author}

Anna I. Zemskova, Deputy Head of the Faculty of Preparation of Foreign Specialists, Junior Scientific Assistant, Postgraduate Department, Volgograd Academy of the Ministry of Internal Affairs of the Russian Federation, Tsiolkovskogo St., 39-72, 400074 Volgograd, Russian Federation, nunufar.07.zema@yandex.ru, https://orcid.org/0000-0003-0265-705X

\section{Информация об авторе}

Анна Игоревна Земскова, заместитель начальника факультета подготовки иностранных специалистов, адъюнкт адьюнктуры, Волгоградская академия МВД России, ул. Циолковского, 39-72, 400074 г. Волгоград, Российская Федерация, nunufar.07.zema@yandex.ru, https://orcid.org/0000-0003-0265-705X 